\title{
Perception Of Accounting Organisations Needs And The Role of Higher Education Institutions
}

\author{
Paulo Oliveira \\ Polytechnic Institute of Maia \\ Sónia Leite \\ Polytechnic Institute of Maia
}

\begin{abstract}
As Community Based Research (CBR) gains currency as a 'research strategy of choice' for the community sector (and increasingly establishes itself as a credible research approach also in the academic sector) we believe there is a need to revisit what have become the conventions of CBR and consider how these are enacted in practice. We could verify that there are several Higher Education Institutions (HEI's) with offices of support services to the community or with this type of goal in their research projects, a demand which is also demonstrated by the organisation that evaluates the HEI's in Portugal. Mainly, the type of problems studied by the community support centers in universities, are related with health, disabilities, and social exclusion. The current investigation is innovative because it was performed in order to identify in what way the accounting organisations need the help of HEI's to provide independent participatory research support in response to concerns experienced by these organisations. Through a questionnaire composed of open and closed questions it was our intention to obtain information regarding the perspective of accounting professionals considering the needs and gaps that they feel in their professional practice and how the HEI's can contribute to help bridge these gaps.
\end{abstract}

Keywords: Community-Based Research, Higher Education Institutions, problems, concerns, solutions

\section{INTRODUCTION}

Over the past 20-25 years a variety of community-based research strategies has gained acceptance as particularly valuable for addressing complex social, health, environmental and poverty issues. This is in part due the acknowledgement that the engagement of the intended beneficiaries of the research is critical to being able to make changes or ensure adoption of research outcomes and recommendations. As CBR is increasingly used as a research process for identifying and addressing social needs and disparities, more attention is being focused on the outcomes of CBR, and whether or not projects are achieving their specific goals and/or the fundamental goals of participatory and action-oriented research. Whether the outcomes of a CBR project are intended or unintended, they need to be documented and analyzed in order for future projects to be more effective in addressing the needs of the groups involved and/or achieving broader social change. An important outcome to assess is that of learning. A fundamental motivation behind community-based research and other associated participatory and action research approaches is the achievement of social change that improves the quality of life for people, or, at least, results in outcomes that address a particular need in a community or organization (J. Green \& Kleiner, 2010). 


\section{WHAT IS CBR?}

The past two decades have seen growing calls for research conducted with-rather than oncommunities. Researchers themselves have often voiced frustration with the limitations of traditional "outside expert-driven" research for gathering data and developing evidence based interventions to address complex health and social problems.

Thus, CBR appears with a long history and diverse intellectual roots that are reflected in the terms variously used to describe it: action research, participatory research, popular education, empowerment research, participatory action research, and others (Strand, Marullo, Cutforth, Stoecker, \& Donohue, 2003). Practitioners of research that is participatory and communitybased come from many different fields in and outside of academia and work in many different parts of the world. According to Strand (2003), the three central features of CBR are:

1. CBR is a collaborative enterprise between academic researchers (professors and students) and community members.

2. CBR seeks to democratize knowledge by validating multiple sources of knowledge and promoting the use of multiple methods of discovery and dissemination.

3. CBR has as its goal social action for the purpose of achieving social change and social justice (Strand et al., 2003).

Summarizing, the concept of community-based research has evolved out of "participatory" and "action" oriented approaches that emphasize the integration of research, education, and action designed to achieve some level of social change as a key outcome. Critical to this type of research is direct participation by people (e.g., individuals, informal groups, organizations) who will be directly affected by the issue being studied. Thus, community-based research is concisely defined as systematic investigation, with the collaboration of the people affected by the problem being studied, for the purposes of education and taking action or effecting change (Green, L. W., 1995).

At the core of CBR is a blend of research approaches that include variations of participatory, action-oriented research, and popular education initiatives (Jordan, 2003). These participatory approaches generally share a set of core principles and characteristics, as clarified by Meredith Minkler and Nina Wallerstein (2008):

It is participatory. It is cooperative, engaging community members and researchers in a joint process in which both contribute equally. It is a co learning process. It involves systems development and local community capacity building. It is an empowering process through which participants can increase control over their lives. It achieves a balance between research and action. (p. 9).

To implement a community-based research project, participation by members of a community or an organization in each step of the research process is critical for maintaining the authenticity of the research as a process of empowerment and a tool for positive social change (Kleiner, Kerstetter, \& Green, 2012). CBR thus not only creates knowledge products but also in itself is a process of learning and development which has the potential to change society through changing individuals and organizations (Wood, 2017).

According to the majority of researchers (Strand et al., 2003), CBR's purpose is to create or discover knowledge that meets a community-identified need, but the role of community members goes further than simply identifying the research topics or question. That being said, the ideal CBR project is one that is fully collaborative-that is, where community people work with professors and/or students at every stage of the research process: identifying the 
problem, constructing the research question(s), developing research instruments, collecting and analyzing data, interpreting results, producing the final report, issuing recommendations, and implementing initiatives. This sort of collaboration means that research roles and relationships are very different from those characterizing conventional academic research, putting every person involved in the same side of the scale. Such research, sometimes, does not involve communities at all. But even when it does, there is typically a clear distinction between researcher and researched, such that the researcher is an "outside expert" with a limited and task-oriented relationship with the community, in contrast to the more multifaceted, informal, and long-term relationship that characterizes CBR. The collaborative nature of CBR makes it a highly effective mode of teaching, learning, and empowerment for everyone involved. Students benefit from the best combination of experiential and intellectual learning strategies. As said above, they are treated and seen as equal members of CBR research "teams" they learn how to listen to others, deliberate about problems and issues, arrive at solutions mutually, and work together to implement them. This sort of collaboration is capacity-building for the parties involved. Training and resources brought to the table by the college or university are transferred to the community partner such that the organization may become self-sufficient and research-capable. Sometimes is the community tht seeks the help of the scholars n not the other way around. Collaboration also enhances the quality of the research, as community members bring to the research table ideas, perspectives, language, and knowledge (Strand et al., 2003).

Yet another reason is pointed out for the increasing attention to research that actively engages local residents and other partners: communities often have sophisticated insider knowledge and understanding that allow researchers to ask the right questions and gather data in ways that will increase the "relevance, rigor and reach" of the findings to effect change (Balazs, Morello-Frosch, Hubbard, \& Ray, 2012).

To sum up, community-based research is an approach to research that is based on a commitment consisting of sharing power and resources and working towards beneficial outcomes for all participants involved. CBR can, therefore, be seen as an umbrella concept that encompasses a variety of participatory research approaches -such as action learning, engaged scholarship, participatory action research, and collaborative inquiry, among others - that actively engages community members and groups in knowledge production processes, ranging from community consultation to initiation and control of research CBR may be led and undertaken by members of community groups and organizations themselves, or more commonly, by community groups working alongside, or in partnership with, professional researchers. Thus, CBR is guided by the core principles of collaboration and partnership where research brings together community and academic expertise to explore and create opportunities for social action and social change (UNESCO, 2015).

\section{THE FOUNDATIONS OF CBR}

There is rich foundation to what we designate as Community Based Research. An extensive body of literature exists, with ancestral roots in action research (Fals Borda, 2006; Reason \& Bradbury, 2006), participatory methodologies (Green L. W., 1995; Minkler \& Weinster, 2008) and community development (Hall H., 2004). Most community-based researchers draw from several common historical and modern strands. The first is the popular education model, which is widely associated with the work of Paulo Freire (1970). Freire advocated for education as a political tool to effect social change at local and global levels, arguing that learning that raises people's consciousness and enhances their understanding of oppressive social conditions can lead to social transformation. The second important influence on current CBR comes from what might be called the participatory research model. This approach grew 
mainly out of liberation struggles in the Third World over the past few decades and has been adapted, as well, to research with traditionally disadvantaged groups. Finally, CBR also traces some of its roots to the "action research" approach introduced by Kurt Lewin (1948), who used it as a tool to increase worker productivity and satisfaction through promoting democratic relationships in the workplace. Lewin's work is considered a more conservative influence on CBR because it de-emphasized community participation and failed to challenge existing power arrangements. The CBR model draws on these diverse historical influences, but also embodies core tenets that make CBR relevant to higher education, especially as a response to the challenges that colleges and universities currently face in exploring partnerships with communities in addressing pressing problems. More recently, the conceptual work by Barbara Israel and others has provided a critical template for what has come to be regarded as the core dimensions of CBR. According to these authors, the key Principles of Community-Based Research are:

1. Recognizes community as a unit of identity.

2. Begins with and builds on strengths and resources within the community.

3. Facilitates collaborative, equitable partnership in all phases of the research, involving an empowering and power sharing process.

4. Promotes co-learning and capacity building among all partners involved.

5. Integrates and creates a balance between knowledge generation and action for mutual benefit of all partners.

6. Emphasis on local relevance of public health and social problems and ecological approaches that address the multiple determinants of disease and well-being.

7. Involves systems development through a cyclical and iterative process.

8. Disseminates findings to all partners and involves all partners in the dissemination process.

9. Involves a long-term process and commitment. (Israel, Eng, Schulz, \& Parker, 1998)

Summarizing, in seeking to appraise the current state of CBR, we touch upon some of these challenges as they relate to three core ideas underscoring CBR: the strength and nature of collaborations and partnerships; the use of participatory methods; and the nature of evidence, outcomes and impacts related to CBR. How these are enacted in current practice provides critical insights into the conceptual and practical limitations of CBR, and lays out the groundwork for new directions.

\section{CHALLENGES IN CBR}

The intention of CBR and other participatory methods has been to ensure the meaningful involvement of community in raising questions of research, giving shape to the application of methods of significance - those techniques that can yield the best information to address the core questions and facilitate action-oriented interpretations (making the evidence speak on a particular issue), and ultimately identifying points for social change and lead communities towards these. As CBR is increasingly used as a research process for identifying and addressing social needs and disparities, more attention is being focused on the outcomes of CBR, and whether or not projects are achieving their specific goals and/or the fundamental goals of participatory and action-oriented research (Kleiner et al., 2012). Stoecker (2005) argues that CBR practitioners often assume that research is primarily causal, and few have experience in producing practical outcomes through research. An effective change strategy embedded in CBR can more likely result in a broader strategy linking knowledge, action, and power. Stoecker proposes a research model grounded in community organizing. The model illustrates a participatory effort to diagnose some community condition, develop a prescription for that condition, implement the prescription, and evaluate the outcomes. He concludes with 
recommendations on training and community relationships for academic researchers to more fully realize the possibilities and benefits of CBR (Kleiner et al., 2012).

As seen in the research by Cook (2008), while CBR is well established in local and international research, in the day to day practices of conducting this work there remain conceptual and operational challenges. Despite the strong conceptual grounding in participatory methods and strategies of action research, the operating principles that guide CBR in practice often remain broad in scope, and are seldom mapped out in explicit terms. At its best, CBR embarks on new territory, illuminating the knowledge that comes with experience, and using these insights helps to construct practical and achievable outcomes that can inform policy issues at the local level (Agency for Healthcare Research and Quality, 2004; Cook, 2008).

Methodologically, CBR offers unique value. Entrepreneurial in spirit, it encourages innovation in research. In the course of promoting greater inclusiveness in research, new strategies and alternative techniques are encouraged for highlighting community perspectives (Minkler \& Weinster, 2008; Salmon, 2007) (Burke et al., 2005). The openness of CBR to new approaches in community engagement and in research has enabled the rapid growth of tools for best practice guides to the pragmatic steps of working with communities in data collection, knowledge translation and dissemination (Macaulay \& Nutting, 2006; Roche, Flicker, \& Guta, 2008). CBR methodology enables researchers to use a wide variety of research methods, including but not limited to photo elicitation, focus groups, semi-structured interviews, participatory mapping, photo voice, and digital storytelling (Jull, Giles, \& Graham, 2017). Despite the powerful arguments endorsing CBR by researchers, funders, and community advocates, however, questions remain about the nature of this research approach in practice, mainly concerning the value of evidence gathered, the integrity or soundness of measurements and its 'scientific credibility' overall (Agency for Healthcare Research and Quality, 2004). The ability to address the issues inherent in CBR and to translate findings into research with impact is in the end a far greater struggle. It is here where the value and promise of CBR is at greatest risk. Also, even though CBR can improve data collection, interpretation, and use to effect change, this approach can be messy, time consuming, and filled with challenges. Building and maintaining partnerships takes substantial time both early on and throughout the research and action processes. Conflicts and power dynamics my occur, they are a challenging but necessary part of community-engaged research. Along the way, trade-offs exist between scientific priorities and community concerns regarding data collection and data-driven interventions. The enhanced cultural sensitivity and relevance of research instruments made possible by high-level community collaboration may also, at times, conflict with outside research partners' desires for the most rigorous possible research designs and study instruments. Community partners may question the relevance of certain scales or may oppose to some kind of data gathering. Even though you can have different outcomes, there's still a long way to go.

\section{Objective}

\section{OBJECTIVE, METHODOLOGY AND PROCEDURES}

The objective of the present study was to analyse, through the application of a questionnaire, the perception of accounting professionals, in the exercise of their duties, about the difficulties they face in their professional practice and their possible settlement in partnership with the Higher Education Institutions. In particular, starting from the research question: What needs do accounting organizations identify that can be addressed with the help of higher education institutions? We want to understand the gaps that accounting professionals feel in research and practice, and identify how higher education institutions can help to overcome the problems encountered. 


\section{Methodology}

The design adopted in this study was the qualitative approach from the application of a mixed questionnaire, aiming to gauge the perception of accounting professionals about the problems that they face in their professional practice and how Higher Education Institutions can help solve those problems.

Theoretical sampling did not start with a defined number of participants, but with directed to a group, the accounting professionals.

A questionnaire consisting of two parts was applied: I - Data related to the characterization of the organization, and II - Specific questions consisting on three open questions, one closed and one using the Likert scale.

The purpose of the questionnaire was to obtain information taking into account the objective of study of the present investigation.

\section{Procedures}

Elaboration of the questionnaire - In the conception of this research instrument, our primary concern was to define exactly the information we wanted to obtain about the difficulties experienced by accounting professionals in their professional practice and how Higher Education Institutions could help to overcome them, obtaining, through the questionnaire, relevant, reliable and valid data on this problem. The questionnaire was built based on the problem raised and the objectives defined for the study. To facilitate the understanding of the survey we grouped the topics that present similar response modalities to ensure the coherence and consistency of the instrument (Thayer-Hart, Dykema, Elver, \& Schaeffer, 2010).

Several attempts - pre-test - were tested to check their suitability for formulating the questions in such a way as to minimize the ambiguity factor and to achieve the highest degree of accuracy so that the subjects addressed understood exactly what they were being asked (Hill \& Hill, 2009).

The results obtained in the pre-test phase were coded and subjected to a simple statistical treatment. To evaluate the internal consistency of the questionnaire, the Cronbach's alpha coefficient was calculated, which is adequate to assess the fidelity of questionnaires formulated with Likert-type scales, (we could see that all dimensions obtained alpha values higher than 0,60 , showing how relevant they are). The opinions of the research advisors on the instrument also assisted in the validation of the questionnaire survey.

Data collection - For systematic data collection 30 questionnaires were distributed.

\section{Sample Characterization}

In the present study, we used a convenience sampling process, which is not a random sample, focusing on accounting professionals in the exercise of their professional activity.

\section{DATA ANALYSIS AND DISCUSSION}

Given that we are dealing with the analysis of questions, we chose to proceed with a qualitative analysis, valuing the content of the answers obtained. We focused on content analysis, (Souza, Costa, \& Moreira, 2016) as it is one of the ways of processing the data. This is the technique that aims to systematically interpret the meaning of any message (textual, graphic, discursive) (Reis, 2017). 
Of the total respondents, $56 \%$ are female and $44 \%$ are male. For the lowest age groups, we have $8 \%$ of respondents under the age of $20,12 \%$ aged between 41 and 50 and $17 \%$ over 50 . Most respondents are between 21 and 30 years old (42\%) and the remainder, 21\%, correspond to respondents aged 30 to 40 years.

\begin{tabular}{clc}
\hline & Characteristics & $\%$ \\
\hline Gender & Female & 56,3 \\
& Male & 43,7 \\
\cline { 2 - 3 } Age & Total & 100,0 \\
\hline & Less than 20 & \\
& 21 to 30 & 8,3 \\
& 31 to 40 & 41,7 \\
& 41 to 50 & 21,0 \\
& More than 50 & 12,1 \\
& Total & 16,9 \\
\hline Schooling & Less than the 9th grade & 100,0 \\
& 9o grade & 5,9 \\
& 12o grade & 7,2 \\
& Degree & 26,9 \\
& Master's degree & 38,7 \\
& PhD & 21,3 \\
\cline { 2 - 2 } & Total & 0,0 \\
\hline
\end{tabular}

By analysing the educational level of the respondents, we can infer that most are graduates and masters, $39 \%$ and $21 \%$ are the percentages of the respective responses to each level of education. Respondents with the 12 th year of training represent $27 \%$, less than the 9 th year represent $6 \%$ and with the 9 th year represent $7 \%$. Still regarding the educational level of the respondents we have none with the $\mathrm{PhD}$ degree.

We can infer that there is a predominance of female respondents and the largest participation in the study is reflected in the age group between 21 and 30. Regarding education most respondents are college graduates.

Thus, as regards the first question, $67,1 \%$ reported representing an office, while the remaining $32,9 \%$ mentioned representing a firm. The vast majority of the organisations reported being in operation for over three years, only $21,7 \%$ reported being in operation for one to three years. Regarding the third question, $71,5 \%$ reported that the organization they represent has less than 5 employees, 23,9\% between 6 and 10 employees and only 4,6\% mentioned having more than 10 employees. When asked about what the main goals of the organization they represent, all respondents stated that it is their goal to inform and advise clients, only $63,2 \%$ also added that it is also their job to support clients. Regarding the fifth question, the following societal problems were identified: "lack of information on taxation like VAT and IRC related issues $38,7 \%$, difficulties in filling out green receipts and what is the role of self-employed workers 8,4\%, relatively low level of knowledge concerning accounting and its applications 33,1\%, uncertainties regarding the rules and procedures for setting up a business 19,8\%. When asked about how often their organization takes actions to address the societal problems it faces, $57,2 \%$ said that it often supports people in terms of goods, services or ideas, $33,9 \%$ mentioned doing so just a few times $8,9 \%$ rarely and no organization has never reported it. Concerning the submission of suggestions for improving social intervention concerning documents and policies $15,6 \%$ have stated doing so just a few times, $7,6 \%$ doing so rarely and $76,8 \%$ never 
doing so. As for the development of educational activities (training, lectures, conferences, others), 5,8\% reported that they do it often, $37,6 \%$ sometimes, $30,8 \%$ a few times, and $25,8 \%$ rarely. Regarding the development of a new solution $6,3 \%$ mentioned doing so many times, $32,9 \%$ sometimes, $40,3 \%$ a few times, $13,4 \%$ rarely and $7,1 \%$ never. Regarding question seven, "does your organization need to do some research to address societal problems?", 83,9\% said yes, while $16,1 \%$ mentioned not needing of any kind of research in the area. Concerning the eighth question, "How can the Academy help your organization to overcome the problems it faces?", The following suggestions were mentioned: getting help in the area of training, not only for internal staff, but also for customers and the general public 13,4\%; help with the development / maintenance / updating of the site 26,2\%; creation of an updated forum or explanatory site $24,5 \%$; creation of a platform with updates / changes to legislation 35,9\%; human assistance, namely from newly graduated technicians or students completing the accounting course for the following activities: document filing; handling of accounting, tax, commercial documents, etc.; organization of the archive according to institutional rules; preparation of receipts, invoicing and other accounting documents; accounting records of documents in the entity's own program; IRS calculation, calculation and simulations; filing electronic tax returns; calculation of the value of VAT (monthly or quarterly).

Finally, when asked about the suggestion for research topics, respondents mostly asked for research on the economic factors by metropolitan area (creation of a database per metropolitan area).

\section{CONCLUSION}

From the above, we can see that, according to the opinions of the interviewed accountants, the Higher Education Institutions can make a favourable contribution towards addressing some of the difficulties experienced by these professionals in their daily practice. Above all, this contribution is related to research, the provision of human resources, particularly at the most critical moments, such as the submission of the IRS declaration or the calculation of the value and filing of the respective VAT returns. Outside the accounting area, IT / Multimedia help was also requested for in some cases related to the creation and maintenance / updating of the organization's website. The creation of a consultation platform aggregating all updated legislative information to be consulted was also suggested. After this work of listening needs, we will share the results with Higher Education Institutions, so that the requests expressed can be followed up and a connection between both institutions can take place.

\section{References}

Agency for Healthcare Research and Quality. Community-based Participatory Research: Assessing the Evidence: Summary, Summary Evidence Report/Technology Assessment 99 § (2004). Washington, DC.

Balazs, C. L., Morello-Frosch, R., Hubbard, A. E., \& Ray, I. (2012). Environmental justice implications of arsenic contamination in California's San Joaquin Valley: a cross-sectional, cluster-design examining exposure and compliance in community drinking water systems. Environmental Health, 11(1), 84. https://doi.org/10.1186/1476-069X-11-84

Cook, W. K. (2008). Integrating research and action: a systematic review of community-based participatory research to address health disparities in environmental and occupational health in the USA. Journal of Epidemiology \& Community Health, 62(8), 668-676. https://doi.org/10.1136/jech.2007.067645

Fals Borda, 0. (2006). Participatory (action) research in social theory: Origins and challenges. London: Sage Publications.

Freire, P. (1970). Cutural Action and Consciencializtion. Harvard Eductional Review, 40(3), 452-477.

Green, J., \& Kleiner, A. (2010). Action Research and Evaluation in Community Development, Pp. 119-39 in Introduction to Community Development: Theory, Practice and Service-learning. Sage Publications, 119-139. 
Green, L. W. (1995). Study of Participatory Research in Health Promotion: Review and Recommendations for the Development of Participatory Research in Health Promotion in Canada. British Columbia: Royal Society of Canada.

Hall H., R. (2004). Organizações: estruturas, processos e resultados (8th ed.). Prentice Hall.

Hill, M. M., \& Hill, A. (2009). Investigação por Questionário (2a). Edições Sílabo.

Israel, B., Eng, E., Schulz, A., \& Parker, E. (1998). Methods in Community-Based Participatory Research for Health. Jossey-Bass.

Jordan, S. (2003). Who Stole My Methodology? Co-opting PAR. Globalisation, Societies, and Education, 1(2), 185200.

Jull, J., Giles, A., \& Graham, I. D. (2017). Community-based participatory research and integrated knowledge translation: advancing the co-creation of knowledge. Implementation Science, 12(1), 150.

https://doi.org/10.1186/s13012-017-0696-3

Kleiner, A., Kerstetter, K., \& Green, J. (2012). Community-Based Research: Analysis of Outcomes for Learning and Social Change. Journal of Rural Social Sciences, 27(2), 1.

Lewin, K. (1948). Resolving social conflicts. New York: Harper and Brothers.

Macaulay, A. C., \& Nutting, P. A. (2006). Moving the Frontiers Forward: Incorporating Community-Based Participatory Research Into Practice-Based Research Networks. Annals of Family Medicine, 4(1), 3.

Minkler, M., \& Weinster, N. (2008). Introduction to Community-based Participatory Research: New Issues and Emphases. Jossey-Bass, 5-23.

Reason, P., \& Bradbury, H. (2006). Handbook of Action Research. London: Sage Publications.

Reis, B. (2017). Os conteúdos em análise-teorias e práticas da análise de conteúdo A transformação da análise de conteúdo no decurso dos tempos, 205-235.

Roche, B., Flicker, S., \& Guta, A. (2008). Exploring the Use of Peer Research in CBR. Paper presented at the CUExpo, Victoria, BC.

Salmon, A. (2007). Walking the Talk: How Participatory Interview Methods Can Democratize Research. Qualitative Health Research, 17(7), 982-993. https://doi.org/10.1177/1049732307305250

Souza, F. N., Costa, A. P., \& Moreira, A. (2016). webQDA - Qualitative Data Analysis (versão 3.0). Micro IO e Universidade de Aveiro.

Stoecker, R. R. (2005). Research Methods for Community Change: A Project-Based Approach. SAGE Publications.

Strand, K., Marullo, S., Cutforth, N., Stoecker, R., \& Donohue, P. (2003). Principles of Best Practice for CommunityBased Research. Michigan Journal of Community Service Learning, 9(3), 5-15.

Thayer-Hart, N., Dykema, J., Elver, K., \& Schaeffer, N. (2010). Survey fundamentals: A guide to designing and implementing surveys. University of Wisconsin.

Wood, L. (2017). The Ethical Implications of Community-Based Research. International Journal of Qualitative Methods, 16(1), 160940691774827. https://doi.org/10.1177/1609406917748276 